\title{
Turismo e consagração dos "Lugares de Memória" nas cidades coloniais e imperiais brasileiras
}

\author{
Tourism and consecration of "Places of Memory" in colonial and imperial \\ brazilian cities
}

\author{
Ivan Rêgo Aragão (ARAGÃO, I. R.) ${ }^{*}$ e Janete Ruiz de Macedo (MACEDO, J. R. de)
}

\begin{abstract}
RESUMO - As cidades do Brasil que surgiram no período colonial (século XVI ao início do século XIX) são detentoras de um conjunto de bens culturais tangíveis e intangíveis, que atraem pessoas de vários locais do país e de outros lugares do exterior. Dessa maneira, a memória dos moradores dessas cidades, também acaba se tornando um atrativo agregado ao patrimônio cultural, trazendo turistas. O presente artigo tem o objetivo de demonstrar que as memórias dos moradores mais antigos podem acrescentar valor ao produto turístico. A metodologia utilizada foi de pesquisa bibliográfica, com revisão de literatura sobre alguns autores no campo teóricoconceitual sobre Turismo, Memória, Cidade, Tradição, Espaço, Lugar e Patrimônio. Ao final, constatou-se que a atividade turística como fenômeno sociocultural pode ser fator de desenvolvimento das localidades, auxiliando na economia e mantendo ativa a tradição e a memória dos moradores.
\end{abstract}

Palavras-chave: Turismo Cultural; Memória; Patrimônio; Cidade; Lugar.

ABSTRACT - The Brazilian cities, which emerged during the colonial period (from sixteenth century to the early nineteenth century) are detainers of a set of tangible and intangible cultural assets that attract people from several parts of the country and elsewhere abroad. Thus, the memory of the residents of these cities, also ends up becoming an added attraction to the cultural heritage, bringing tourists. The present paper aims to demonstrate that the memories of the older residents can add value to the tourism product. The methodology used was bibliographical research, with literature review using some important authors in theoretical and conceptual Tourism, Memory, Town, Tradition, Space, Place and Heritage. In the end, it was verified that the tourist activity as a social and cultural phenomenon may be a factor of localities development, helping the economy and keeping alive the tradition and memory of these residents.

Key words: Cultural Tourism; Memory; Heritage; City; Place.

\footnotetext{
* Graduação em Turismo pela Estácio/Faculdade de Sergipe (FaSe), com ênfase em cultura, patrimônio, identidade, turismo cultural, religioso e planejamento do turismo. Mestrando em Cultura e Turismo do Programa de Pós-Graduação Stricto Sensu da Universidade Estadual de Santa Cruz (UESC), Ilhéus/BA, com bolsa da Coordenação de Aperfeiçoamento de Pessoal de Nível Superior (CAPES). Técnico em Conservação de Bens Culturais Móveis da Fundação de Arte de Ouro Preto (FAOP). Endereço: Av. Francisco Porto, 239/902 Ed. Villa D'oro. CEP: 49020-120 - Aracaju - Sergipe (Brasil). Telefones: (79) 3232-2206/9139-9652. E-mail: ivan_rego_aragao@yahoo.com.br

** Licenciatura em História pela Universidade Federal de Pernambuco (UFPE). Graduação em Pedagogia (UESC). Especialização em História Moderna e Contemporânea pela Pontifícia Universidade Católica de Minas Gerais (PUCMG). Doutorado em História da Antiguidade Clássica pela Universidad de Léon (Espanha). Professora Livre Docente da UESC e do Mestrado em Cultura e Turismo. Endereço: Campus Prof. Soane Nazaré de Andrade Km 16 - Rodovia Ilhéus-Itabuna. CEP: 45662-000 - Ilhéus - Bahia (Brasil). Telefone: (73) 3680-5043. E-mail: janetermacedo@yahoo.com.br
} 


\section{INTRODUÇÃO}

De modo geral, as cidades trazem em seu cotidiano aspectos da cultura, da sociedade e da economia dos seus moradores, que as tornam únicas quando comparadas a outros lugares. Mas as cidades coloniais e imperiais brasileiras tais como São Cristóvão (Sergipe); Parati, Petrópolis (Rio de Janeiro), Pirenópolis (Goiás); Ouro Preto, Serro do Frio e Tiradentes (Minas Gerais); São Luís do Paraitinga (São Paulo), entre outras, além destes fatores ditos acima, também possuem uma carga histórica bem demarcada. Esse fato torna o passado dessas cidades, lugares potenciais em atrair pessoas na busca de conhecimento cultural e sentido de identificação. Dessa forma, a cultura e todo o seu legado, fazem desses locais produtos potencialmente prontos para serem formatados pela atividade turística. Somado a isso, a memória dos moradores se torna evidenciada como algo que agrega valor a experiência do visitante. Nas cidades que deram origem e contribuíram para a formação do Brasil, aspectos como a arquitetura (FOTOS 1, 5 e 6); arte sacra (FOTO 2); festas, celebrações religiosas (FOTO 3) e de folguedos populares (FOTO 4); culinária; dentre outros, auxiliam na construção de um turismo calcado nos valores culturais, no resgate do passado e no desenvolvimento da economia.

O presente artigo tem como objetivo demonstrar que as memórias dos moradores mais antigos podem acrescentar valor ao produto turístico. Para tanto, foi feita uma pesquisa bibliográfica, com revisão de literatura sobre alguns autores no campo teórico sobre Turismo Cultural em Barretto (2007), Brito (2009), Meneses (2006) e Portuguez (2004); Memória em Bosi (1987), Meneses (1992), Meyer (2009), Nora (1993) e Polack (1992); Cidade em Certeau (1994), Lopes (2009) e Pesavento (2002); Tradição em Hobsbawn (2002); Espaço em Cruz (2003); Lugar em Augé (1994); Patrimônio em Alfonso (2003), Luchiari (2005), Paes (2008), Perdigão (2008), Scifoni (2006) e Zanirato (2006 e 2009).

Ao final da pesquisa, constatou-se que a atividade turística como fenômeno sociocultural, é fator de desenvolvimento das localidades, auxiliando na economia e mantendo ativa a tradição e a memória dos moradores. 


\section{A CIDADE}

Partindo do princípio de que toda cidade possui uma carga histórica desde a sua gênese e valores culturais inerentes no contexto das práticas sociais, os lugares trazem em si aspectos determinantes dos atos civilizatórios dos moradores. Na concepção de Marc Augé (1994, p. 76) o "lugar se configura como lugar" [...] "do sentido inscrito e simbolizado, o lugar antropológico" [...]. Refere-se a ele "[...] pelo ao menos a um acontecimento (que ocorreu), a um mito (lugar-dito) ou a uma história (lugar histórico)". Com o passar do tempo, as cidades tornam-se lugares com um ambiente propício para diversas manifestações de caráter cultural, de produção de bens e identidade coletiva.

Todo lugar é histórico e se produz a partir de preceitos culturais, que variam ao longo do tempo, fazendo com que a paisagem apresente a adição de momentos distintos da evolução social. Em outras palavras, pode-se dizer que a paisagem é a somatória de tempos distintos, do homem e dos demais elementos da natureza, que se conjugam e, por vezes, produzem lugares capazes de serem utilizados para fins de recreação (PORTUGUEZ, 2001, p. 81).

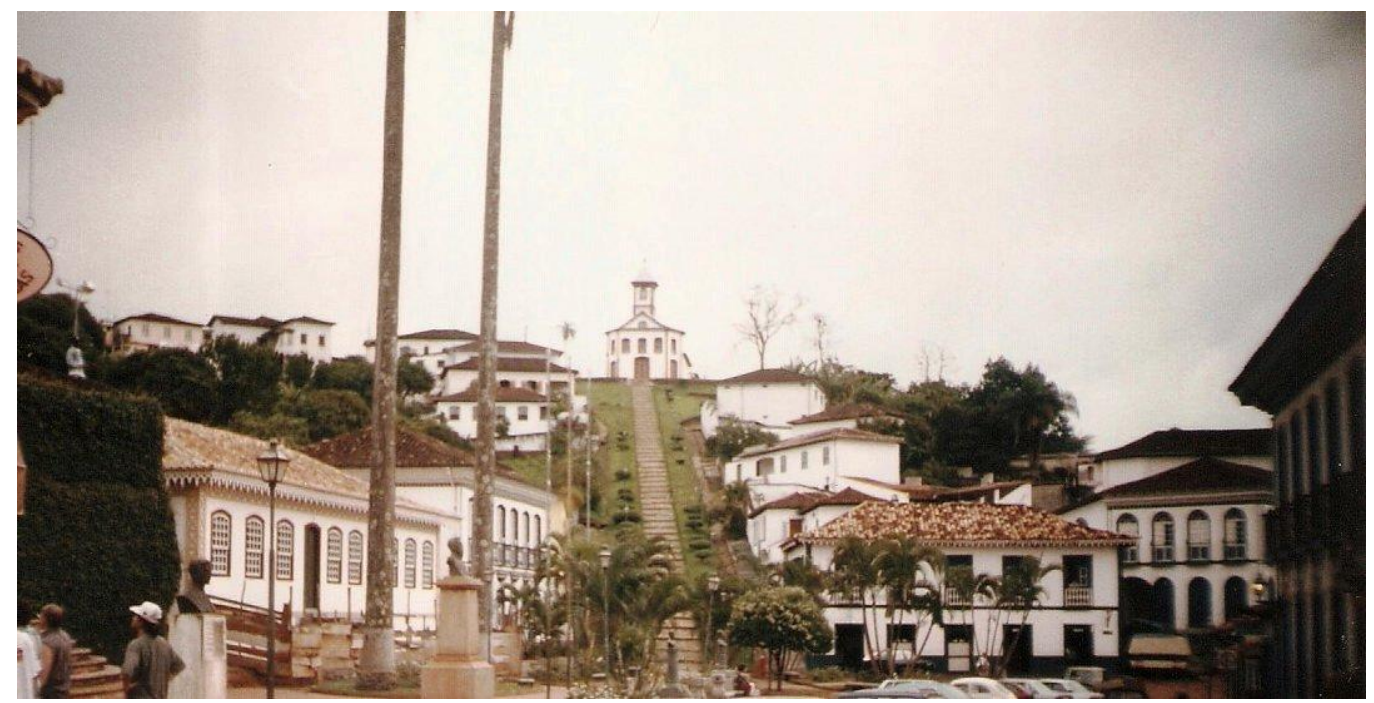

FOTO 1 - SERRO DO FRIO EM MINAS GERAIS (BRASIL)

AUTORIA: IVAN RÊGO ARAGÃO, 2000

Essa gama de manifestações que resultam na cultura local - quer seja ela material ou imaterial - acaba sobremaneira se tornando atraente para o turismo no espaço urbano. Acrescentando as memórias, histórias e tradição das cidades, formata-se 
um produto potencial para ser mostrado e divulgado, a partir dos seus aspectos singulares.

Nesse contexto, o espaço urbano das cidades proporciona experiências culturais latentes, haja vista que, as cidades coloniais e imperiais do Brasil possuem uma memória histórica impregnada de sentidos. Percebidos em sua arquitetura, ritmos e sons dos grupos de folguedos e danças populares, na sua gastronomia típica e nas suas manifestações religiosas singulares. Manifestações herdadas de Portugal e Espanha, guardadas na memória dos moradores e sendo passadas de "pai para filho". Com a transmissão de saberes se desenvolvendo dentro da comunidade, E. P. Thompson (1998, p. 18) demonstra que também, “[...] dá-se igualmente a transmissão de experiências sociais ou da sabedoria comum da coletividade".

O turismo como atividade relacionada ao fluxo de pessoas, pode auxiliar no intercâmbio de diferentes culturas e assim, modificar o cotidiano dos lugares visitados e dos seus residentes e estes, influenciarem quem chega para conhecer a cidade.

\begin{abstract}
Os conceitos de urbano, processo de urbanização ou fenômeno urbano se desenvolveram dentro das ciências sociais, que, por sua vez, constituíram seus objetos e estabeleceram seus respectivos métodos analíticos a partir do século XIX, em pleno florescimento da Revolução Industrial - que, alterando os modos de produção, entre outras coisas, reorganizou o espaço, demarcando, com nitidez, o urbano em oposição ao rural - e forte desenvolvimento do sistema capitalista (LOPES, 2009, p. 399).
\end{abstract}

Com a visitação de lugares relevantes para o turismo, o patrimônio cultural incluso nestes locais - estimula várias formas de utilização dos espaços, principalmente para o visitante que desconhece a cidade e quer explorar o seu ambiente urbano. Visto que, o:

[...] ambiente urbano, enquanto lócus de concentração populacional é um dos lugares privilegiados de expressão dos suportes materiais e simbólicos produzidos e reproduzidos pelos grupos humanos. A cidade distingue-se como um espaço de vivências, de experiências que conformam as culturas e as práticas de sociabilidade [...] (ZANIRATO, 2006, p. 4).

Nas reflexões sobre a urbe, primordialmente "a cidade, é por excelência, o 'lugar do homem', ela se presta à multiplicidade de olhares entrecruzados que, de forma transdisciplinar, abordam o real na busca de cadeias de significados" (PESAVENTO, 2002, p. 9). "Planejar a cidade é ao mesmo tempo pensar a própria pluralidade do real" 
(CERTEAU, 1994, p. 172). Dentro das novas abordagens teórico-conceituais, a cidade tem sido percebida como local não apenas das práticas do capitalismo e de acumulação de riquezas, é também um lugar de pesquisa interdisciplinar, um campo de conhecimento onde se congregam vários saberes.

\begin{abstract}
As cidades são os lugares que concentram a maioria das pessoas. Elas possuem formação espontânea ou projetada, de vários portes e todas têm sua história construída através do tempo. Em todas podemos perceber aspectos singulares que se expressam nos seus planos, formas, cores, movimentos, sons, arranjos espaciais e relações com a natureza entre outros. As cidades podem se mostrar sob múltiplas facetas em sua complexidade [...] (PERDIGÃO, 2008, p. 226).
\end{abstract}

A cidade ainda suscita que, a população mais antiga, acabe tornando-se um atrativo à parte de toda uma gama de equipamentos turísticos: um "atrativo humano" junto com o passado da cidade sendo evocado pela lembrança dos moradores. Nesse contexto a memória seria:

[...] a formação de imagem necessária para os processos de constituição e reforço da identidade individual, coletiva e nacional. [...] processo psicosocial de representação de si próprio, que reorganiza simbolicamente o universo das pessoas, das coisas, imagens e relações, pela legitimidade que produz. A memória fornece quadros [...] de intercâmbio social (MENESES, 1992, p. 22).

\title{
3 O TURISMO
}

O turismo como somatório de várias ações que envolvem o deslocamento às cidades, torna-se um fenômeno de integração de diversos setores humanos. Focado no âmbito sociocultural, vislumbrasse uma atividade que necessita de planejamento incessante de médio e longo prazo. Procurando viabilizar um turismo participativo que inclua a comunidade, o mesmo trará desenvolvimento para as cidades, bem como, o fortalecimento do sentido de pertença do morador, um melhor uso do patrimônio local, das potencialidades e equipamentos turísticos.

Entendendo todo o legado como sendo referente "às pessoas, às origens e a história de uma comunidade. Prega-se aqui a necessidade de preservar o patrimônio e reforçar a identidade das pessoas e dos lugares em primeiro lugar" [...] (PORTUGUEZ, 
2004, p. 8). A cultura em todas as suas dimensões tem sido fator essencial na construção de produtos atraentes para os locais. Através dos bens tangíveis e intangíveis, a mesma também tem suscitado a formatação de atrativos para o consumo turístico, auxiliando no resgate da tradição, da memória. Nessa relação paradoxal entre bens culturais e o turismo, encaixa-se toda uma postura de combate ao turismo massivo e degradante, para evitar que produza mais desigualdade social e pobreza.

O turismo promove trocas entre os indivíduos de diferentes origens. E ao propiciar o encontro de pessoas, o turismo se apresenta não só como fenômeno econômico, mas também sociocultural. A atividade é capaz de envolver o fluxo de pessoas em diversas regiões e nichos culturais, e, é através desse contato, que se estabelece também uma aceitação de outros costumes. O turismo promove o intercâmbio entre diferentes culturas (com o contato entre o turista e os residentes locais) (DIAS, 2005), resultando disso mais compreensão e respeito mútuos, tolerância em relação a valores, hábitos e costumes diferentes, aceitação da pluralidade cultural como um aspecto importante da humanidade.

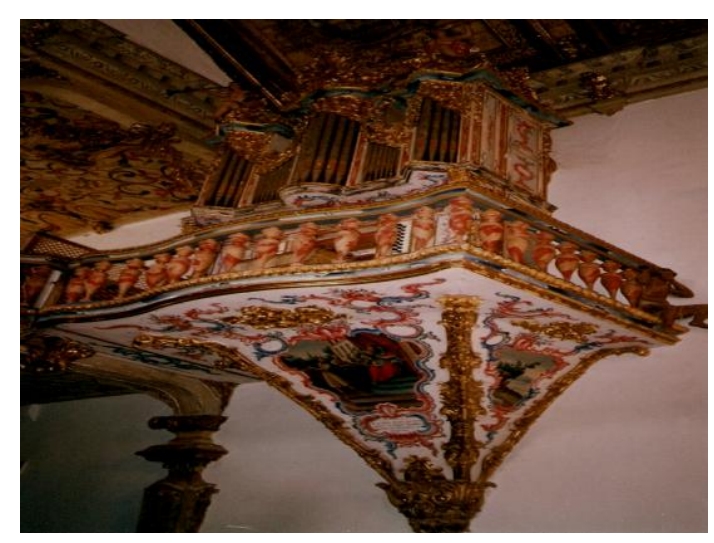

FOTO 2 - ÓRGÃO DA IGREJA MATRIZ DE SANTO ANTÔNIO / SÉC. XVIII. (TIRADENTES - MG) AUTORIA: IVAN RÊGO ARAGÃO, 2000

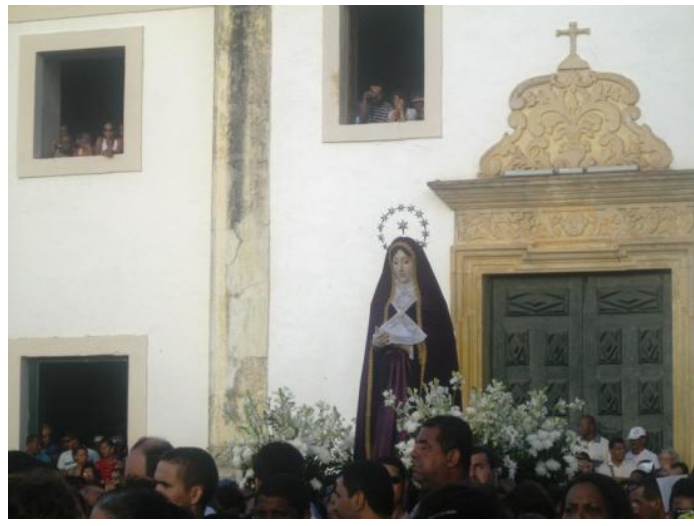

FOTO 3 - FESTA/PROCISSÃO DE NOSSO SENHOR DOS PASSOS. (SÃO CRISTÓVÃO - SERGIPE) AUTORIA: IVAN RÊGO ARAGÃO, 2011

Atualmente, o interesse pela identidade, diz respeito à percepção dos atores de que seu lugar no mundo passa por investimentos simbólicos, pelos quais eles se afirmam e negociam com outros sua forma de inserção na sociedade (BURITY, 2002). Além disso, num mundo globalizado, o diferencial entre os grupos, instituições e indivíduos passa cada vez mais fortemente pela cultura, de forma que esta se torna uma 
perspectiva obrigatória de discussão do que são e para onde vão as sociedades contemporâneas. O turismo como fenômeno social, vai propor também experiências de aprendizado e respeito entre esses dois agentes ativos, não demarcando nem impondo a cultura do mais forte a do mais fraco.

\section{A MEMÓRIA E O TURISMO}

Os seres humanos têm sentido a necessidade de criar lugares de memória (NORA, 1993), de enquadrar locais para a posteridade, numa tentativa de congelar o passado, a herança das antigas populações e conservar o patrimônio cultural para as gerações futuras. Seria uma crise na memória? O fato é que com o advento da revolução tecnológica, das mídias digitais, bem como da evolução nos meios de comunicação, é possível perceber uma maior dependência no armazenamento das informações históricas produzidas pelo seres humanos. Essa afirmação vale para a cultura em todas as suas dimensões.

O homem atualmente necessita criar esses espaços, visto que, "se habitássemos ainda nossa memória, não teríamos necessidades de consagrar lugares” (NORA, 1993, p. 8). Tudo isso está conectado ao que se denominou de "indústria do patrimônio cultural” (MENESES, 1992, p. 2), onde atualmente impera o desejo por registrar os acontecimentos nos mais variados suportes, porque a memória está sendo cada vez mais externalizada. Defendendo a idéia de necessidade de cristalização da mesma e como fator inerente aos seres humanos, Michel Polack menciona que,

[...] a memória é um elemento constituinte do sentimento de identidade, tanto individual como coletiva, na medida em que ela é também um fator extremamente importante do sentimento de continuidade e de coerência de uma pessoa ou de um grupo em sua reconstrução de si (POLACK, 1992, p. $5)$.

Eugenia Meyer (2009) faz uma análise da memória como princípio essencial a orientação humana. Mostrando que, a mesma torna-se eficaz em mostrar o rumo e o sentido de viver. "O objetivo da memória seria dar sentido as nossas vidas. [...] trata-se permanentemente de lutar contra o esquecimento, para impedir que a memória chegue a um fim, a um término, à sua conclusão" [...] (MEYER, 2009, p. 43). O patrimônio das 
cidades quer seja ele tangível ou não, contem essa função: de manter viva a memória do grupo através dos espaços e construções seculares, das festas e comemorações. O enraizamento da memória se dá em uma escala territorial - em alguma paisagem, em algum lugar. "É no espaço material e da memória que a identidade permanece enraizada" (PAES, 2008, p. 162).

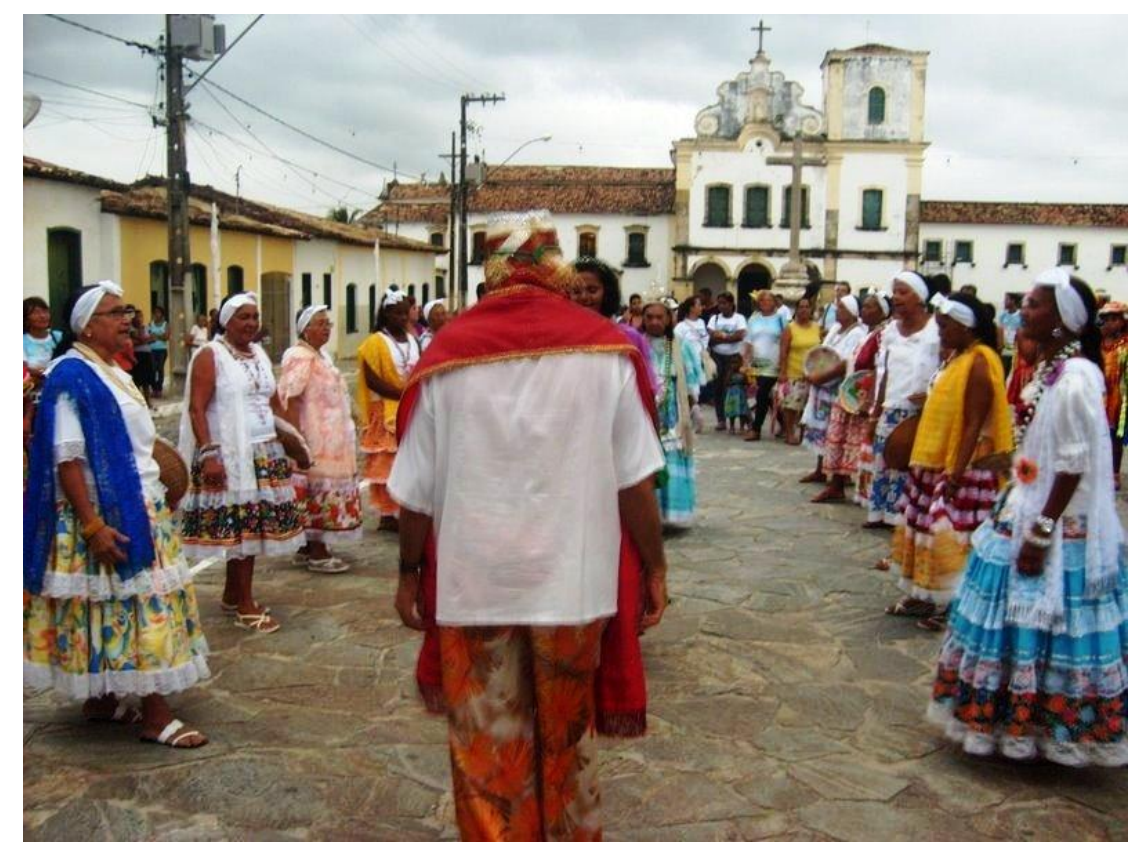

FOTO 4 - GRUPO DE TAIEIRAS

SÃO CRISTÓVÃO, SERGIPE (BRASIL)

AUTORIA: SÓCRATES PRADO, 2009

Nas cidades com uma carga histórica acentuada, é possível perceber nos moradores mais antigos que o passado, torna-se fator de rememoração constante e, dessa forma, "a memória permite a relação do corpo presente com o passado e, ao mesmo tempo, interfere no processo 'atual' das representações" (BOSI, 1987, p. 9). Representações de caráter sociocultural que, quando bem trabalhadas, podem se tornar um "produto" do turismo. A memória também passa a ser constituinte de valores que fazem dela única e fator de estudo, pesquisa e atração cultural. Em documento do Ministério do Turismo (BRASIL, 2008, p. 16), se encontram afirmações que se encadeiam com a idéia de que "a vivência histórica das comunidades, ao ser valorizada pelo turismo, enriquece a experiência do turista e reforça o sentimento de pertença local". Nesse contexto, a instituição acima citada, traça o perfil do visitante predisposto a essa forma de turismo, informando que: 
O turista cultural valoriza a cultura em toda a sua complexidade e particularidade, movimentando-se em busca de ícones que representem a identidade local e a memória coletiva. Ambos os conceitos remetem a um conjunto de experiências, fatos históricos e elementos culturais comuns a um grupo ou comunidade, e que podem ser representados pelos bens culturais materiais e imateriais que compõem o patrimônio (BRASIL, 2008, p. 17).

\section{O TURISMO CULTURAL NAS CIDADES COLONIAIS E IMPERIAIS DO BRASIL}

O turismo cultural surge como forma contrária ao turismo de massa, visto que o turista dessa modalidade prima pela valorização do saber e por experiênciar a autenticidade do cotidiano de um local (BARRETTO, 2007). Ainda segundo a autora citada, esse segmento turístico diz respeito às características relacionadas à cultura humana, tais como a história, o cotidiano, "ou qualquer dos aspectos abrangidos pelo conceito de cultura" (BARRETTO, 2007, p. 87).

O turismo cultural em essência, também pode ser denominado de turismo de resgate, visto que, essa forma de turismo voltada para a área cultural visa perceber "as atividades turísticas relacionadas à vivência do conjunto dos elementos significativos do patrimônio histórico e cultural e dos eventos culturais, valorizando e promovendo os bens materiais e imateriais da cultura" (BRASIL, 2008, p. 10). Marcelo Brito (2009), faz uso do pensamento da Unesco (United Nations Educational, Scientific and Cultural Organization $)^{1}$ ao enunciar que, o turismo cultural além de,

[...] colaborar para realçar a diversidade cultural em contraposição aos processos de homogeneização derivados do mundo globalizado em que vivemos, visto que essa atividade se realiza em função do diferente, do exótico, do curioso e, por isto, pode se constituir em um instrumento para o intercâmbio entre culturas (UNESCO, 2006 apud BRITO, 2009, p. 231).

As cidades coloniais brasileiras, em sua maioria, acumulam um conjunto de bens culturais, tornando-se quase sempre locais de mediação entre o presente e o passado.

A cada período da evolução técnica, o meio sofre interferências que rompem progressivamente os moldes culturais materializados no espaço, fazendo com que o novo e o antigo coexistam e revelem o seu caráter dinâmico. [...] esse

\footnotetext{
${ }^{1}$ UNESCO. Tourisme, culture et développement durable. Paris: Unesco, 2006.
} 
patrimônio deixado pela sociedade em momentos passados pode-se tornar de grande interesse de estudo, de conservação, de memorização e, inclusive, de operacionalização turística (PORTUGUEZ, 2001, p. 82).

Dessa forma, os lugares urbanizados com características evidenciadas pela história do Brasil (coloniais e imperiais), tornam-se conseqüentemente espaços de enquadramento de memória e de valorização da identidade sociocultural brasileira. As cidades "são, também, atrativas para o turismo, por tudo aquilo que representam, como 'obras de arte' das sociedades humanas como lugares de encontro, do ir e vir, do acontecer do modo geral" (CRUZ, 2003, p. 16).

No Brasil, os lugares que surgiram a partir da colonização feita pelos portugueses e espanhóis, possuem características diferenciadas no seu código de construção. As cidades desse período são um:

[...] conjunto de ambientes construídos em diferentes tempos históricos, cujas necessidades humanas eram bem distintas das atuais, de modo que as formas urbanas, na atualidade, chamam a atenção, tanto pelo seu caráter funcional original, quanto por sua aparência, que difere do modo de viver da sociedade pós-moderna, na qual o mundo de hoje se insere (PORTUGUEZ 2004, p. 3).

Alguns desses espaços foram planejados à feição do traçado urbano ibérico tendo dois níveis: a cidade alta quase sempre o local onde se concentrava o poder político e religioso, e a cidade baixa, lugar do comércio e do porto. A predominância da "arquitetura colonial/barroca" atrai visitantes para conhecer as construções feitas pelas gerações passadas. Somando-se a esse fator, esses locais muitas vezes, herdam tradições inventadas, visto que são redutos de celebração do passado, da herança e dos bens culturais advindos de Portugal e Espanha, do continente europeu como todo, e ainda, do Brasil nos seus primórdios quando da chegada dos colonizadores.

Por "tradição inventada" entende-se um conjunto de práticas, normalmente regulares por regras tácita ou abertamente aceitas; tais práticas, de natureza ritual ou simbólica, visam inculcar certos valores e normas de comportamentos através da repetição, o que implica, automaticamente; uma continuidade em relação ao passado (HOBSBAWN, 2002, p. 9).

No processo de evolução das cidades, o turismo feito no meio urbano quando planejado, tem auxiliado sobremaneira na demarcação da cultura local e das diferenças culturais entre regiões e países, reforçando dessa forma, a identidade específica dos 
espaços visitados. Na chamada "cultura do encontro" (ALFONSO, 2003), entre indivíduos de diferentes origens, hábitos e costumes, são desenvolvidas muitas nuances de interação, tais como a valorização do patrimônio material, com as edificações e os bens culturais móveis, e dos aspectos intangíveis da cultura, incluindo as danças, o folclore, a gastronomia e a religiosidade. O sentido de patrimônio na modernidade, [...] "surge como um artifício criado no sentido do fortalecimento de uma pertença ao espaço simbólico, atribuindo uma transcendência a determinados símbolos culturais que atestam o caráter singular de uma determinada comunidade" (BOMFIM, 2009, p. 127).

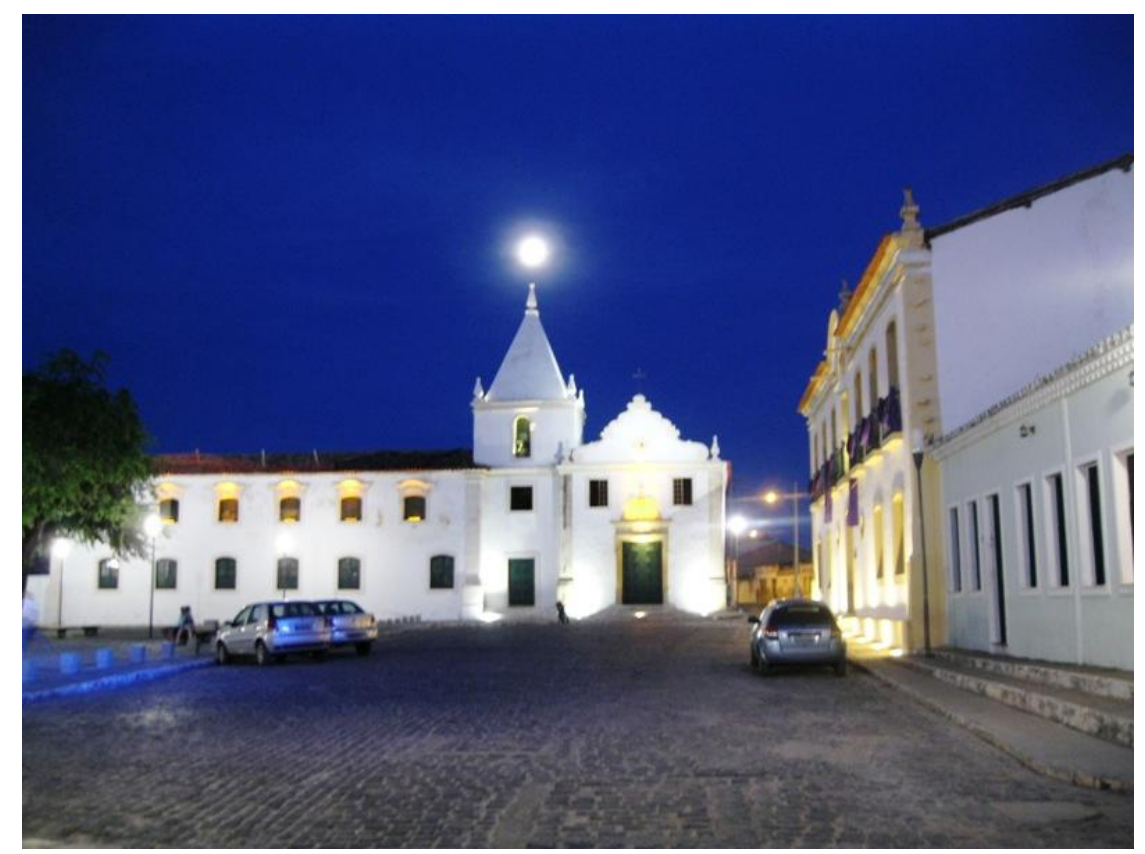

FOTO 5 - ANTIGA IGREJA E SANTA CASA DA MISERICÓRDIA, SÉC. XVIII

SÃO CRISTÓVÃO - SERGIPE (BRASIL)

AUTORIA: IVAN RÊGO ARAGÃO, 2011

Para Maria Tereza Luchiari (2005), essa súbita valorização pelo patrimônio cultural é revestida de um caráter muito mais capitalista, de acúmulo de riqueza e exclusão social, não interessando as questões de caráter cultural, de resgate e de pertencimento da comunidade.

A revalorização das paisagens constituídas por elementos históricos, como o patrimônio arquitetônico, tem atribuído às paisagens urbanas contemporâneas um novo sentido no campo do consumo cultural. O patrimônio arquitetônico tornou-se, hoje, cenário revestido de valores mercadológicos, descompromissados com o passado e com o lugar [...] (LUCHIARI, 2005, p. 95). 
Simone Scifoni (2006) tem outra visão ao perceber que, essa revalorização por locais e sítios antigos que se tem visto por todo o Brasil, seria uma maneira do brasileiro conhecer o seu próprio patrimônio cultural, desconhecido para a grande maioria.

O interesse do turismo pelo patrimônio pode ter um significado positivo contribuindo para a sua proteção física e recuperação, além da divulgar sua importância estimulando, assim, a inserção dos bens na dinâmica social, dando-lhe uma função e retirando-os da condição de isolamento (SCIFONI, 2006, p. 5).

Nesse sentido a atividade turística, acaba por contribuir com a perpetuação da memória da população e na conservação do patrimônio cultural dentro dos lugares de atração turística e, ainda, pode auxiliar na ativação da economia local. Na concepção da autora acima citada, "o patrimônio além de outros setores da cultura tornou-se, na contemporaneidade, um poderoso instrumento na lógica da produção capitalista da cidade" (SCIFONI, 2006, p. 6).

A partir dos usos dos bens culturais definidos pelo fluxo de pessoas - moradores e visitantes, - pode-se entender a dinâmica do turismo local no aproveitamento dos espaços de socialização e com fortes tendências ao encontro de culturas diversas. Dentro das cidades, é possível verificar um "leque" de opções para o uso dos espaços: quando do uso turístico, o mesmo quase sempre está relacionado às construções antigas, com seus estilos únicos e que se tornaram fonte de nostalgia e pesquisa para estudiosos e para o visitante, que vem atrás do resgate e aperfeiçoamento cultural. Essa forma de utilização dos espaços está relacionada à eleição de lugares de referência em detrimento de outros, visto que, o homem também os propaga e os transforma em espaços de produção turística. Quando os espaços são usados socialmente significa que:

[...] correspondem aos modos socialmente construídos para a participação da sociedade em geral na identificação, conservação, estudo e difusão dos bens que configuram a sua identidade. Isso implica que a população se sinta identificada com os elementos a serem conservados, que se reconheça neles, para que eles se tornem, de fato, representativos dela e para ela. O reconhecimento do pertencimento coletivo dos bens acarreta esforços comuns para sua conservação e, quanto mais coletivo e representativo eles forem, mais protegidos estarão (ZANIRATO, 2009, p. 3). 
É próprio do homem se apropriar de espaços e transformá-los em algo que interesse ao cotidiano do lugar (MENESES, 2006), e nesse sentido, o consumo e o uso das construções no ambiente são culturais.

\section{CONSIDERAÇÕES FINAIS}

$\mathrm{Na}$ análise do turismo enquanto atividade social e cultural percebe-se que o mesmo oferece uma gama de possibilidades para se trabalhar o resgate da identidade e do sentido de pertença da população de um local. Através do conjunto de bens culturais concentrados nas cidades coloniais brasileiras, é possível perceber as singularidades da cultura material, como o patrimônio arquitetônico, bens culturais móveis (arte sacra, objetos museais, dentre outros). Nessa perspectiva é possível desenvolver também como atrativos do turismo, os aspectos da cultura imaterial, como danças, folclore, música, gastronomia, religiosidade e as memórias dos moradores mais antigos, todos em favor da atividade turística.

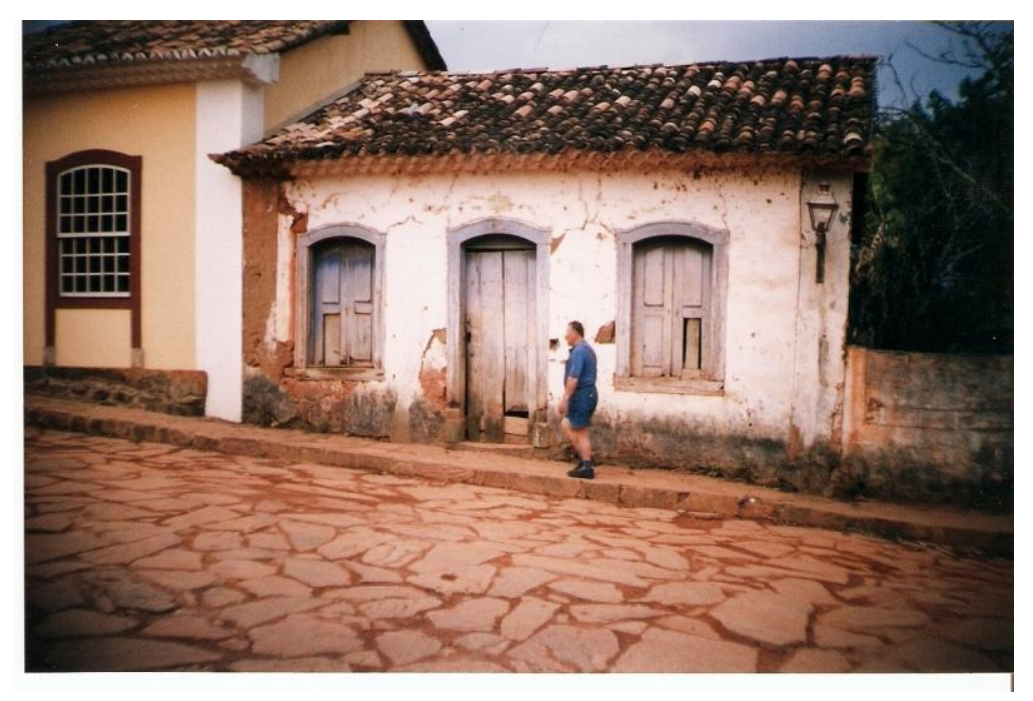

FOTO 6 - CASARIO EM TIRADENTES-MG

AUTORIA: IVAN RÊGO ARAGÃO, 2002

Como fenômeno econômico, o turismo cultural põe em evidência um leque de especificidades locais prontas para serem divulgadas e comercializadas, a partir do patrimônio material e imaterial das cidades com características predominantemente 
históricas. Auxiliando na ativação da economia local, na maior auto-estima dos moradores, na formação cidadã e como meio de sobrevivência da população. Nesse sentido, faz-se necessário planejar a atividade para que esta não se torne degradante das culturas locais, e, acabe perdendo a sua razão de ser frente ao capitalismo desenfreado.

As cidades mais antigas do Brasil (coloniais e imperiais), tais como São Cristóvão, Parati, Petrópolis, Pirenópolis, Ouro Preto e São Luís do Paraitinga, entre outras, trazem em si a possibilidade de se trabalhar o turismo cultural. São lugares que além de um conjunto de bens materiais como a arquitetura, os objetos de bens móveis, de arte aplicada e de saberes presentes no cotidiano das festas, da religiosidade, do folclore popular e da gastronomia, trazem como legado, a memória dos habitantes que se misturam ao próprio sentido funcional da cidade. Sempre há um morador antigo, que já faz parte da paisagem da cidade, que tem estórias para contar, ou mesmo algum andarilho que usa a rua como casa e se tornou figura "folclórica": ora como "louco", ora como "exótico", mas com uma carga popular intensa, se incorporando ao cenário do lugar.

Acreditando no perfil diferenciado do turista enquadrado no segmento cultural, ao conhecer a memória dos residentes mais velhos de uma comunidade, é possível conhecer todo um leque de tradições e costumes que atestam as especificidades das cidades. O patrimônio cultural dos lugares vai além da cultura material, visível e palpável, existe todo um legado que corrobora para os locais urbanos tornarem-se únicos, singulares com os aspectos histórico-sociais e de sentimento de pertença da população. As características que distinguem um ambiente urbano de outro, auxiliam na construção de um turismo calcado no valor cultural e identitário, no resgate do passado e no desenvolvimento das economias locais.

\section{REFER̂̂ENCIAS}

ALFONSO, M. J. P. El patrimonio cultural como opción turística. In: Revista Horizontes Antropológicos. Porto Alegre, ano 9, n. 20, 2003.

AUGÉ, M. Não-lugares: introdução a uma antropologia da supermodernidade. 2. ed. Campinas: Papirus, 1994. 
BARRETTO, M. Cultura e Turismo: discussões contemporâneas. Campinas: Papirus, 2007.

BOMFIM, N. R. Patrimônio, turismo e planejamento: formatação de produtos. In: CAMARGO, P. de; CRUZ, G. da. Turismo Cultural: estratégias, sustentabilidade e tendências. Ilhéus: Editus, 2009.

BOSI, E. Memória e Sociedade: lembrança dos velhos. 2. ed. São Paulo: Editora da Universidade de São Paulo, 1987.

BRASIL, MINISTÉRIO DO TURISMO. Diretrizes para o desenvolvimento do turismo cultural. 2. ed. Brasília: MTur, 2008.

BRITO, M. Turismo cultural sustentável: certificação de destinos turísticos de dominância patrimonial. In: CAMARGO, P. de; CRUZ, G. da. (Orgs.) Turismo Cultural: estratégias, sustentabilidade e tendências. Ilhéus: Editus, 2009.

BURITY, J. A. Cultura e identidade: perspectivas interdisciplinares. Rio de Janeiro: DP\& A, 2002.

CERTEAU, M. de. A invenção do cotidiano. 4. ed. Petrópolis: Vozes, 1994.

CRUZ, R. de C. A. da. Introdução à geografia do turismo. 2. ed. São Paulo: Roca, 2003.

DIAS, R. Introdução ao Turismo. São Paulo: Atlas, 2005.

HOBSBAWN, E. A invenção das tradições. In: HOBSBAWN, E; RANGER, T. (Orgs.) A invenção das tradições. São Paulo: Paz e Terra, 2002.

LOPES, D. M. F. Cidades pequenas são urbanas? O urbano possível. In: Bahia Análise \& Dados, Salvador, v. 19, n. 2, jul./set. 2009.

LUCHIARI, M. T. D. P. A Reinvenção do patrimônio arquitetônico no consumo das cidades. In: Geousp - Espaço e Tempo, São Paulo, n. 17, 2005.

MENESES, J. N. C. História \& turismo cultural. Belo Horizonte: Autêntica, 2006.

MENESES, U. T. B. de. A história, cativa da memória? Para um mapeamento da memória no campo das ciências socais. In: Revista do Instituto dos Estudos Brasileiros. São Paulo, n. 34, 1992.

MEYER, E. O fim da memória. In: Revista dos Estudos Históricos. Rio de Janeiro: FGV, vol. 22, n. 43, 2009.

NORA, P. Entre memória e história. A problemática dos lugares. Revista Projeto História. São Paulo: Pontifica, Universidade Católica, n. 10, 1993. 
PAES, M. T. D. Patrimônio cultural, turismo e identidades territoriais: um olhar geográfico. In: BARTHOLO, R.; SANSOLO, D. G.; BURSZTYN, I. (Orgs.) Turismo de base comunitária: diversidades de olhares e experiências brasileiras. Rio de Janeiro: UFRJ, Letra e Imagem, 2008.

PERDIGÃO, C. O patrimônio arquitetônico, os sítios históricos e o turismo. In: Gestão da Cadeia Produtiva de Turismo. Universidade Aberta do Nordeste, fascículo 14. Fundação Demócrito Rocha, Fortaleza, 2008.

PESAVENTO, S. J. O imaginário da cidade. 2. ed. Porto Alegre: UFRGS, 2002.

POLACK, M. Memória e Identidade Social. In: Revista dos Estudos Históricos. Rio de Janeiro: FGV/CPDOC, v. 5, n. 10, 1992.

PORTUGUEZ, A. P. Consumo e espaço: turismo, lazer e outros temas. São Paulo: Roca, 2001.

- Turismo, Planejamento Socioespacial e Patrimônio Histórico Cultural. In: PORTUGUEZ, A. P. (Org.). Turismo, memória e patrimônio cultural. São Paulo: Roca, 2004.

SCIFONI, S. A Unesco e os patrimônios da humanidade: valorização no contexto das relações internacionais. In: JACOBI, P.; FERREIRA, L. da C. (Orgs.). Diálogos em ambiente e sociedade no Brasil. São Paulo: Annablume, 2006.

THOMPSON, E. P. Costumes em comum: estudos sobre a cultura popular tradicional. São Paulo: Companhia da Letras, 1998.

ZANIRATO, S. H. Patrimônio para todos: promoção e difusão do uso público do patrimônio cultural na cidade histórica. In: Patrimônio e Memória. São Paulo: Unesp, v. 2, n. 2, 2006.

Usos sociais do patrimônio cultural e natural. In: Patrimônio e Memória. São Paulo: Unesp, v. 5, n. 1, 2009.

Recebido em: 27-02-2011.

Aprovado em: 27-03-2011. 